\title{
What future for ethical medical practice in the new National Health Service?
}

\author{
Rajendra D Persaud Bethlem Royal and Maudsley Hospitals, London
}

\section{Author's abstract}

\begin{abstract}
The British Government is implementing some major alterations to the way health services in Great Britain are organised. As well as the introduction of competition between health care providers, their financial interests are to be linked to their output, in efforts to use market forces to increase efficiency and cut costs. This paper looks at the possible impact of these changes of health care organisation on ethical medical practice. This is investigated with particular reference to the country whose health service has embraced most closely these elements of the market - the United States of America. The question to be answered is whether high standards of ethical care are ensured by factors somehow intrinsic to the medical profession, and are therefore immure to changes in the economics of health care. This assumption is shown to be questionable in light of what is known about the determinants of ethical medical practice.
\end{abstract}

\section{Introduction}

The concerns of medical ethicists usually revolve around debating the morality of some particular issue such as euthanasia, abortion, resuscitation, confidentiality and embryo research. Most published essays have therefore taken what may be termed the 'quandary' approach to medical ethics. A premise of this perspective is that the primarily ethical motivation of health care providers is not usually in question, and thus the possibility of ethical mismanagement only arises in especially perplexing situations.

However, just as a particular case can be analyzed from an ethical perspective, so can a system of health care delivery. The outcome of such an analysis may be to suggest that economic, social or political forces are working to make unethical practice an inevitable part of that system. No one particular medical decision would have to come under scrutiny, but the contexts in which thousands of medical decisions are made could

\section{Key words}

Medical ethics; health economics; medical education; National Health Service reforms; rationing; allocating scarce resources. be analyzed critically to investigate the pressures on widespread ethical behaviour.

There are special difficulties with this kind of analysis which the 'quandary' approach does not share. Without detailed knowledge of each individual case, as is usually available in the 'quandary' method, judging the way large numbers of providers deliver ethical care requires enough information to ensure the circumstances involved have been explored sufficiently and pre-judgement has been avoided. It could be argued that the sheer volume of such information would make it difficult to acquire or comprehend. Another problem is that direct evidence of clearly pervasive unethical practice would be difficult to obtain by its very nature. A further issue is that of cultural relativism in ethics, which arises when analyzing the way other communities handle health care.

However, these difficulties do not diminish the importance of the endeavour. All health care delivery systems adopt positions implicitly or explicitly on certain ethical issues such as whether health is a human right, and on what principles of equity and social justice health care resources should be distributed. Thus any discussion or implementation of changes in a nation's health service must include an analysis of the ethics of care such a system will generate.

Yet the main preoccupation of the British Government's review of the National Health Service is the place of financial considerations in clinical decision-making (1). Laudably its aim is to increase efficiency, and therefore treat more people with the money saved. One central, implicit assumption of its proposed changes is that the great tradition of doctors acting in their patients' best interests will continue unaffected. All the proposed changes depend on this assumption for their predicted effects. The validity of this assumption depends on exactly what are the determinants of ethical medical practice. This question seems still largely unexplored empirically, and even theoretically. Due to its developing importance for the future of health care, this paper attempts such an analysis.

The proposed changes to the British health service concentrate on the introduction of competition between health care providers and also linking their 
financial interests to their care provision (1). The National Health Service was previously organised on a basis which directly attempted to keep these elements out of health care. One way of examining how these proposed changes will influence ethical practice would be to examine their effects in other systems where they are allowed free reign, such as in America.

Such a comparison would have to allow for confounding variables such as differences between the two systems in levels of medical litigation. However, it could be argued that many of these 'confounding' variables, such as levels of defensive medicine, arise from values which naturally develop in a competitive system. The investigation of implicit values is thus essential in many respects to understanding the full ramifications of a market approach to health care.

Due to the medical knowledge imbalance between doctor and patient, evaluation of performance of the profession is difficult for patients. Thus the usual reasons why markets act as checks to ensure quality operate here poorly. Instead the ethical standards of the profession are used as a means of ensuring patients' interests will be looked after. The determinants of physicians' ethical behaviour then become of crucial importance because the control that is exercised normally by informed buyers is replaced by physicians' internalised values in a health market.

\section{How do market forces affect medical ethical behaviour?}

The notion that market forces produce and distribute goods and services more efficiently than other systems has been employed as a solution to several economic problems. In attempts to tackle rising costs of health care, the introduction of market forces into the health service has appeared an attractive solution. It seems very efficient to let everyone in health care compete, and may the best enterprise win. The unsound should fail and the good succeed. The health system which comes closest to employing this model in its purest form can be found in America. Those concerned about the possible effect on medical ethics of market forces should therefore be interested in the American experience.

In a system whereby doctors are paid per patient seen and treatment administered, one would predict that there would be economic pressure on doctors to supply treatment to patients, even when patients do not need it. This activity would come under the description of 'supplier-induced demand' and there is much evidence that this occurs in America.

Studies conducted over the last 25 years have consistently found that a substantial fraction of hospital use is inappropriate in the USA (2). For example in one study of six widely different geographical locations studying 100 hospitals and over 1000 admissions, 23 per cent of admissions were judged by independent medical opinion to be inappropriate and an additional 17 per cent to have been avoidable by the use of ambulatory surgery (2).
When the relationship between doctor/population ratios and the extent of doctor-initiated return visits has been investigated in America, several surveys have found strong positive relationships. Areas with more doctors tended to have a much larger proportion of return visits arranged by the doctor, indicating that the more doctors have to compete with each other for 'work', the more they 'induce' demand for health care (3).

One utilisation study recently reported that 17 per cent of coronary angiography procedures, 32 per cent of carotid endarterectomies and 17 per cent of upper gastrointestinal endoscopies performed on patients at five sites across the USA were considered inappropriate by expert panels of doctors (4).

Another study found that internists in several large fee-for-service groups were doing 50 per cent more electrocardiograms and 40 per cent more chest $\mathrm{x}$-rays in uncomplicated hypertension patients than internists in two non-fee-for-service organisations (5). A study of a Medicare (a government insurance scheme) fee freeze during the early 1970s showed that even when fees were frozen, Medicare expenditures continued to rise as quickly as before fee controls were instituted, because doctors responded by providing more services (3).

Partly because of this 'supplier-induced demand' the costs to American society of health care have risen precipitously; by the end of 1987 health care expenditures in the United States had passed the halftrillion-dollar mark, at $\$ 511$ billion (6). Doctors share the major responsibility for generating these huge costs to society, and they have also been the main beneficiaries. Probably more than 70 per cent of all expenditures for personal health care in America are the result of decisions of doctors (7), whose earnings account for 20 per cent of total health care costs (6). The prediction for US health expenditures in 1990 was that they would rise to $\$ 640$ billion (6). But there are other even more cynical explanations of how American doctors generate these high health care costs.

For example, the practice of insurance fraud in plastic surgery whereby cosmetic work is charged to insurance companies under the guise of treatment for diagnoses which they will reimburse, such as 'biopsies' and 'hernia repairs', has been described as 'prevalent' and 'frequent' in America (8). Furthermore it has been excused as doctors '.. only responding to the competitive challenge' (8).

In a questionnaire study to investigate American doctors' attitudes toward the use of deception, almost 70 per cent indicated they were willing to deceive an insurance company to secure an insurance payment (9). Generally, when forced to make difficult ethical choices, most of the doctors studied indicated some willingness to engage in forms of deception (9).

The magnitude of gifts to doctors from medical suppliers is great. So much so that when a US beer company recently sacked several senior executives for violating the company's policy against accepting gifts 
from firms with which the company did business, one medical journal questioned whether the beer company was more ethical than the American medical community (10). US doctors similarly receive large sums from medical suppliers (10). Some ophthalmologists for example accept large inducements from manufacturers of intraocular lens implants to use particular brands of lenses. These include quantity discounts, cash rebates, shares of stock in the company and a variety of gifts, such as free vacations, the use of yachts, and expensive office equipment (11). The costs of these inducements are of course in the end passed onto the patient via the increased cost of lenses.

Throughout the profession, large 'kickbacks' are available for referring patients to particular specialist centres. The levels of reimbursement reached such levels that eventually they were made illegal by federal law in 1972 in response to widespread fraud and overuse of insurance programmes by doctors (12). These referral arrangements are now disguised as business partnerships or as 'consulting' arrangements. In one recent case doctor investors stood to make more than $\$ 100,000$ over a five-year period based on nothing more than a $\$ 10,000$ promissory note 'paid' as an 'investment' in a magnetic-resonance-imaging partnership (13). Other not dissimilar schemes abound, for example one large hospital chain substantially increased the use of its operating theatres by sharing the profits with its staff surgeons (11).

Thus doctors' fees continue to increase at nearly double the rate of inflation (14) and the median net annual income for US doctors in 1988 was $\$ 92,000$ (15). Even academics enter commerce with enthusiasm, hiring themselves out as consultants, forming private companies of their own or entire research institutes financed by health service corporations (16). When a national random sample of the American public was questioned about doctors' pay, 70.1 per cent thought doctors were overpaid (14). The study concluded that Americans felt their doctors' incomes were unfairly high for the contribution they made to society (14).

One response to these spiralling costs in American health care has been the introduction of costcontainment policies. Under one new scheme hospitals are paid a preset price by insurance agencies for services based on average costs of hospital care for patients in 'Diagnostically Related Groups' (DRGs). The principle has been to fix reimbursement for treatment to a standard charge per diagnostic entity, so that even if doctors or hospitals want to charge more for the care of a patient with that diagnosis, they will only be reimbursed the pre-fixed amount. The effect of this system is to remove the financial interest of care providers in treatment and in its place to substitute an opposite incentive - the restriction of care.

The very same doctors who were criticised for providing unnecessary services in a fee-for-service environment are now entrusted not to under-serve their patients in the face of direct economic incentives to do so. In 1986 the US Senate Special Committee on Aging charged that not only were DRGs driving patients out of hospitals quicker and sicker, but also patients were receiving false and incomplete information about their rights under the new system (17).

As 'DRG' cost of treatment calculations are based on average costs of treatment for patients with those illnesses, very sick patients with the same or related diagnosis will account for most hospital financial losses. More than half of all hospital losses have occurred in 2.8 per cent of cases under this scheme (17). Clearly hospitals have an incentive to avoid admission of the very sick. Thus a perverse social incentive is created: the desire on the part of hospitals to avoid patients who need their services most (17). However, for obvious reasons hospitals do not report the numbers of individuals to whom they have denied care (17). But some idea of the way hospitals have changed their ethical perspective on this aspect of care provision is that in 1940 philanthropy accounted for 24 per cent of the total operating budget of non-profit hospitals in New York City; by 1948 it had dropped to 17 per cent. According to the United Hospital Fund of New York, its share is now barely 1 per cent (18).

The crucial need for philanthropy arises because often the neediest have no health insurance. In America today there are 37 million people without any health insurance at all (19). About a third of these are children under the age of 18 (20). In 1982 it was estimated that more than one million people were directly refused health care services and another four million did not even seek care, although they may have needed it (21). In a 1986 study 13.5 million Americans reported they did not receive medical care for financial reasons (22). Even those who are eligible for government help or 'Medicaid' have problems because large numbers of doctors refuse to participate in the scheme because of the low reimbursement fees paid by Medicaid (23).

Thus there exist many 'financially undesirable' patients which hospitals and doctors attempt to avoid. One hospital strategy for dealing with unprofitable patients in emergency departments is to prohibit their admission; this is termed 'economic triage' (24). When in 1986 the New York chapter board members of the American College of Emergency Physicians called upon the college publicly to condemn 'economic triage' the college replied;

'... The harsh facts are that a substantial number of EDs (emergency departments) would close along with hospitals if all transfers for economic reasons were stopped ...' (24).

Thus most of the new pressures to cut costs introduced by the competitive health care market, like DRGs, ultimately depend on the co-operation of health care providers in lowering health care expenses. However, 
health care providers also face the temptation to pursue their economic self-interests in ways that may be easier but less ethically desirable: hospital 'dumping' of the uninsured; premature discharging of patients when their DRG payments run out; reduced quality of care, pushing sales of un-needed high-profit services and cutting back on needed services that are a financial loss.

Another possible ethical issue arising from this type of organisation of health care is the risk of economic coercion of patients by doctors: for as large numbers of Americans' insurance or income does not allow them access to medical care, some may be vulnerable to extreme inducements to obtain care. There are no recent examples in the literature but during 1946 and 1947 six patients with good renal function were injected with increasing doses of uranium-234 and uranium-235 to determine the dose necessary to produce renal damage. The patients were mainly chronic alcoholics, homeless, and emotionally disturbed - and one was having hallucinations. The carrot for taking part was a warm bed in hospital (25). Certainly this example of economic coercion of patients by doctors lies closer in time to the Third Reich than to our own times - but warning spectre it remains.

Beyond the behaviour of doctors acting as individuals in the health market, associations of doctors also are affected, groups who would normally be expected to campaign on behalf of patients. A large number of medical organisations and societies have become largely dependent on corporations in the health market for income in America. A recent editorial in a medical journal complained about the fiscal dependency of the American Medical Association on industry and pointed out that, interestingly, the AMA has also been one of the staunchest opponents of attempts to introduce national health insurance in America, and even set up a private fund to lobby against it (16). What is possibly ethically questionable about this is that it appears to be an attempt by the profession to influence political decisions about health care towards their own interests and away from that of the general public, for whom doctors are supposed to be natural advocates. Public opinion polls showed in 1987, as did those of previous years, that the majority of Americans believed everyone should have equal access to health care regardless of their ability to pay (22).

Another ethical problem for the health market is its inevitable relationship to advertising. Recently $R D$ Rice, President of the Television Bureau of Advertising in America, stated that 'the health care category (of advertising) was one of the fastest-growing and most important in local television' (26). American health care companies spent 125.6 million dollars on television advertising in 1985 (26). In some areas of America 25 per cent of television advertising is now devoted to medical products and services (27). In a newspaper article S Jacobs, President, Healthware Images, commented: '.. physicians, hospitals, dentists - these are all businesses. They have to approach their audiences the same way that Coca-Cola does ...' (26). However medicine, unlike most other products, is an extremely complicated service. Yet advertisements by their very nature simplify, and inevitably all simplification contains an element of potential deception. Furthermore, self-promotional advertising introduces the element of 'caveat emptor' (let the buyer beware) into what should be primarily a caring relationship built on trust.

Advertising is also implicitly comparative and seeks to emphasise differences between what may be largely similar products. Advertisements naturally imply that competitors in health care provision are inferior and this would lead to a general lowering of public faith in the profession. However, in the USA recently, a representative of the Federal Trade Commission suggested that if direct advertising to the public did weaken patients' trust in their doctors, that could be a very good thing, since it might induce patients to 'shop around' for doctors (28). When surveyed, a majority of the American public (58 per cent) did not expect advertising by physicians to be either truthful or honest (22).

Other ethical dilemmas arise out of the inevitable comparisons of mortality and morbidity statistics between institutions trying to attract patients. For example, pressure is put on American surgery programmes only to operate on good-risk cases to ensure better results (29).

Evidence that damage has been caused to the profession's ethical reputation by their activities in the market place includes the fact that since the middle 1960 s, public confidence in the leaders of medicine and health institutions has fallen dramatically, from 73 per cent to 33 per cent (22). These percentages relate to the number of Americans expressing a 'great deal of confidence' in the leaders of medicine (22). Furthermore most Americans (68 per cent) report they have been increasingly losing faith in doctors (22).

A fundamental problem with the health market is that it introduces its own set of priorities and methods of dealing with medical care which changes the whole character of the activity to one essentially of a commercial transaction. Eventually health care comes to be judged along the lines of other materialistic concerns, so that the whole moral language that deals with caring is pushed aside. For example, in surveys, the quality of hospital care is ranked by the US public as better than that of 'automotive repair shops', but worse than that of supermarkets and airlines (22).

\section{Are medical ethics 'traditional'?}

It might be argued that what will protect ethical medical practice, whatever its economic context, is the tradition of medical ethics within the profession. 'Sacred' traditions of a profession which have a long history might be relied on to ensure certain standards of behaviour even in difficult situations.

However, traditions of medical ethics do not stretch 
back continuously into history as may be commonly believed. For example, the Hippocratic oath was peculiar to only one of several schools of medicine in antiquity, and its tradition was virtually forgotten until it was reintroduced to a few guilds in Europe by the Arabs in the eleventh century (30). Only in the nineteenth century, with the development of scientific medicine and the competition amongst doctors, surgeons and apothecaries for professional dominance, did the oath re-emerge as the basis of the doctors' code of practice. It was an attempt at that time to invest medicine with a respectable image based on a scientific and ethical tradition going back to the Greeks (31).

What is possibly more important than the discontinuity of the tradition of medical ethics is that most attempts to codify ethical practice in history were very concerned with the conflicts of interest which arose between doctors and patients on the 'business' side of medical practice. In the code of laws of Hammurabi from 1790 BC doctors' fees were regulated, and surgical fees were set according to the social status of the patient (32). A considerable portion of the 'Precepts' of the Hippocratic corpus for example provides recommendations about how to conduct the 'business' aspects of one's practice. The moral keynote of Hippocrates was that the 'business ethic' must not interfere with the 'treatment ethic'. For example he says:

'So one must not be anxious about fixing a fee. For I consider such a worry to be harmful to a troubled patient ...' (33).

Similar concerns may be found in other professional codes intended to regulate medical ethical behaviour, such as the influential Percival's Medical Ethics published in England in the 18th century (34) and the American Medical Association's Code of Ethics published in 1847 (34). The contents of these attempts to introduce codes of ethics throughout the history of medicine testify to the profession's eternal struggle to regulate conflicts of interests between 'business' and 'caring'. That this struggle is modern and alive can be seen in the multiplicity of codes of ethics issued regularly by the World Medical Association since 1948 (35). For example, from the International Code of Medical Ethics comes the statement;

'A physician shall not permit motives of profit to influence the free and independent exercise of professional judgement on behalf of patients' (35).

Thus the history of the tradition of ethics in medicine, as seen through various published codes of practice, recognises the importance of economic considerations to the delivery of health care. These traditions may be viewed therefore as codified reactions to the reality that without regulation of some kind, doctors share a merely human vulnerability to economic influences.

In the most recent edition of the American Medical
Association's code of ethics there are statements regarding technical competence but these do not really differentiate medicine from business (36). In 1988 a US doctor and a medical student commented on this code in the Fournal of the American Medical Association thus:

'Where are the professional values? Where are the noble ideals of obligation, service, and mercy? Where is the acknowledgement of the intrinsic worth of each individual? Where is the acknowledgement of our indebtedness to both our patients and society for our education? The answer is that these have been weeded out in the 140 years since the American Medical Association's first code of ethics' (36).

\section{Can medical ethical behaviour be taught?}

A questionnaire study of members of the American Occupational Medical Association found that ethical conflicts were perceived as relatively frequent occurrences in practice. Most respondents stated that in dealing with these ethical conflicts they relied heavily on their education and training. The teaching that their primary duty should be to their patient was heavily influential (37). This raises the question of whether training in medical ethics can be relied on to sustain and improve ethical standards in the profession regardless of countervailing economic pressures. There is a need to make a distinction here between possible improved understanding of ethical issues because of ethics teaching, and its impact on actual ethical practice.

In the United States there is great interest in ethics teaching in medical schools (38). Almost all US medical schools have ethics as part of the curricula. A recent affirmation of the importance of medical ethics by the Association of American Medical Colleges in 1984 secured its place in their medical schools for the future (38).

Beyond teaching ethics, many American medical schools have instituted other mechanisms for inculcating ethical behaviour in the doctors they produce. For example, in one survey 54.5 per cent of medical schools had established humanistic criteria such as honesty and aiding others to be used alongside academic criteria in the evaluation of their students (39). In one medical school, on the very first day of their training, medical students are presented with a statement of ethics which they must sign and return, acknowledging they have read and understood the document (40).

Certainly medical ethics - as a subject - is well established in American medical education at all levels (41). Papers appear regularly in the literature and major professional associations have ethics committees which provide guidelines on the questions faced by their members (41). 'Ethicists' are usually present on conference platforms as well as committee rosters, and the principal American medical texts carry chapters on ethics (41). In many hospitals ethicists make regular 
consultation rounds, attend internal medicine rounds and are involved in regular ethics conferences (42).

However, the ethos of medical education prevalent in America is that medical students learn primarily from their observations of the role models provided by senior doctors whom they accompany on wards. Ideally clinicians do not 'teach' ethics but rather seek to set an example that will lead those who watch to behave in an ethical manner (43). The difference between what is taught about medical ethics and what goes on in the wards is then a crucial problem for ethical education. That such a gap exists is suggested by the evidence already presented on the influence of market forces on doctors' behaviour. Added to this are the following recent comments on American medical ethical education by a US professor of ethics in medicine:

'The medical student, who has learned something about, say, the principle of patient autonomy, follows a team in which the cascade of clinical events overwhelms any concern about patients' preferences' (41).

'I do not accuse the academic medical centre of unethical practice but only of being the place where the carefully refined tenets, learned in academic medical ethics ... are almost systematically extinguished. The academic medical centre is like the tavern that stands around the corner from the church; a sermon on temperance, however eloquent, can hardly overpower the impulse to drop in and have a drink' (41).

Despite all the concern for ethics instruction expressed in American medicine, its relative failure to impact on practice in the face of market forces, is summarised by a recent chairman of the Association of American Medical Colleges who declared in 1989:

'But overriding all of the aforementioned threats to our traditional covenant with society are the changing values and erosion of trust emanating in large part from the competition model of delivering and financing medical services' (4).

There is in fact little empirical evidence that medical ethics teaching is effective in the sense of influencing. doctors' behaviour towards more ethical practice when this conflicts with their own material interests, as frequently occurs in the market system of health care delivery (44). Thus much of the motivation encouraging medical ethics teaching in such an economic system probably stems from a realisation of the required greater need for positive ethical influences on doctors.

Unfortunately it seems more an intuitive hope that such teaching will influence ethical behaviour than an actually demonstrated fact.

\section{Discussion}

Are there ethical arguments for introducing market ideology into health care? There is a set of assumptions on which an ethical foundation for the health market is usually built. It is suggested that people can do many things themselves to stay healthy both in avoiding selfinjurious activities and in taking part in healthpromoting behaviour. Usually people freely choose their behaviour and therefore their own risks. However, people who do take risks with their health impose wrongful financial burdens on others. Therefore it is argued no one has the right to force others to pay for their unhealthy behaviour. Furthermore, when health care is consumed by a patient, those resources, though beneficial to that person, may arguably often be put to better use elsewhere by others. The thrust of these arguments is to suggest it is ethical to let people be in charge of their own interests and thus take their own financial responsibility for spending on health care, and then allow health care providers to compete for this.

There are many problems with this argument, not least being that although something is known of what people can do to stay healthy, for practically everyone health remains uncertain and ultimately we all become unhealthy to the point of dying. However, another key concept here is the notion of wrongful burden. As a result of self-injurious behaviour do some individuals impose unfair increased costs on others?

Already various insurance and taxation schemes incorporate the concept of 'wrongful burden' and seek to exclude or penalise those who represent increased costs to others. However, the ethical justification for this depends not only on a high degree of uncertainty about which specific behaviours lead to 'wrongful burdens' but also the ability to apportion definite individual responsibility for such actions. In the case of health care, how is the individual responsibility for a large number of diseases, not least those with a hereditable component, to be decided? Is it ethical to allow health provision systems claiming 'wrongful burden' to opt out of the care of such people?

Despite this argument, some may still conclude that 'wrongful burden' schemes offer intrinsically fairer health resource allocations for the individual than rival schemes. However, 'wrongful burden' may lead to ethically unacceptable consequences for a community, for example, by jeopardising minimally acceptable standards of health care available to all. Furthermore this loss may put at risk the whole community via, for example, communicable diseases. Similarly unpalatable consequences for a society could follow the application of 'wrongful burden' notions to the provision of other services, such as police, fire and the military.

Taken to its logical conclusion as an ethical principle, 'wrongful burden' would call into question the very notion of a redistributive taxation system. Perhaps the most serious consequence of all would be the selfish value system ultimately generated.

Thus, while notions of 'wrongful burden' may have their place in taxation schemes on self-injurious 
behaviours, they seem a questionable justification for refusing to provide for others' health care. This may not only be ethically undesirable but even a practically impossible way of living.

There are further ethical problems which arise out of supposed benefits of market approaches to health care. Markets may prove seductive to doctors, as in such a system the financial position of doctors is usually hugely enhanced. This naturally arises because in the exchange of goods and services that occurs in a free market, doctors monopolise skills which command enormous bartering power. However, large economic disparities tend to have detrimental effects on the chances of equal moral relations between people. Thus a side-effect of this large material disparity which arises between doctors and the rest of society in the free market, is to reduce further the already limited opportunities for equity in this relationship.

A further ethical problem of the market approach is the ambiguity it exploits concerning doctors' principal loyalties when conflicts arise between what the patient desires and what is in the patient's interests. Patients often want unnecessary and possibly dangerous treatments, medicines, care and tests, but the doctor should be consistently and unambiguously loyal to patients' interests. This obviously presents problems in a free market where supplying what the patient wants, rather than what the patient actually needs, will frequently result in greater reward for the doctors.

Society has three main ways of dealing with situations in which self-serving economic behaviour produces socially undesirable results. The first is for individuals to recognise the need for socially responsible and ethical decisions and to govern their own actions accordingly. This has been tried in the American system and, according to the evidence produced here, found wanting in many respects. The second approach is for intervention to regulate the private market, to change its financial incentives so that good business becomes good social policy. This has also been tried in America with DRGs and was also found to be an inadequate solution.

The common reason for the failure of these two methods is the erroneous assumption that traditional medical ethics and medical ethical education would govern doctors' behaviour when conflicts of interest arose.

The third approach, which has been up to now the British solution, is to recognise the importance of encouraging ethical practice by removing economic conflicts of interest from doctors' practices and thus to replace the private market altogether with government institutions.

Thus Britain's National Health Service has worked on the basis of implicit agreements between state and medical profession. The state allocated budgets to health authorities which in turn, set spending limits for individual hospitals. Thus the state achieved firm control over health care spending and the medical profession retained clinical autonomy. The state could not determine the way in which resources were used with individual patients; doctors had to accept budgetary limits set for them. For the state it was politically astute to arrange that health rationing should be disguised as clinical decisions, as in the case of end-stage renal disease treatment for example (45). However, doctors who save money by restricting treatment in this system, unwittingly become guardians of taxpayers' money. Yet how do doctors know that money saved on one of their patients is put to better use elsewhere by the taxpayer?

All societies ration medicine, the decision to do so is not the fundamental ethical dilemma health care providers face. Societies differ only in how they ration medicine, and it is this choice between methods of rationing which raises ethical questions. There is general agreement that all current systems of health care function sub-optimally. To some observers discontent with a system, this is sufficient to compel change as they feel whatever takes its place could hardly be less efficient or less equitable. However, there is enormous potential for harm in virtually any step that might be taken.

What can be learned from examining the determinants of ethical practice is the realisation that all systems of health care need to develop a comprehensive system of allocation that is concerned not only with justice in 'micro' dilemmas concerning which individuals will get a specific treatment, but also with justice in 'macro' decisions regarding the share of societal resources devoted to health. Doctors may wish to abdicate responsibilities for ethical problems in health rationing by leaving it to society to decide when to refuse doctors' demands on behalf of their patients. However, no principles of justice will ever entitle any patient to unlimited treatment, which thus denies others who are sick, or even those who are healthy but hungry or homeless. Doctors therefore have mixed obligations to be both advocates for their patients, and sparing users of society's resources.

Thus the most important rationing role and ethical responsibility of doctors is helping as health care professionals to shape the entire health care delivery system in which they work.

If they don't, others' attempts to control costs will impose accountability schemes with a simplistic view of doctors' practice. Alongside the growing emphasis on both sides of the Atlantic on assessing the effectiveness of specific medical procedures, there has been a developing belief in altering health care systems to reward providers for the quality and effectiveness of their care. While attempting to measure quality of care is a worthwhile endeavour, how does one measure ethical standards of care? A reliance on rewarding the easily measurable may ensure that equally important but less quantifiable aspects of care disappear. Precisely because they are difficult to monitor, their absence may not be noticed until it is too late. And yet the professional standing of the doctor rests no less on ethical commitment than on technical competence. 


\section{Conclusion}

Any system of health care that claims to be rational should seek to preserve and enhance those elements in medicine that have proved of most value over time. To do otherwise is dangerous to the health of patient and profession. It is therefore important that the impact of any cost-containment measure on medical ethical behaviour is evaluated. One need not assume that every doctor is a passive actor awaiting new directing, nor that as a group they are particularly grasping. One need only observe how patterns of social forces tend to orientate professional relationships in particular directions.

Carved on the lintel of the temple of Asklepios were the words:

'A doctor must be like a god: serving equally rich and poor, male and female, slave and citizen.'

But even gods sometimes need a little help.

\section{Acknowledgement}

I would like gratefully to acknowledge the help of the psychiatry residents at Johns Hopkins University Hospital, Baltimore, USA. Their open discussions during my stay there, from January to June 1990, were instrumental in my understanding of the practical effects of the market approach to health care.

Rajendra D Persaud BSc MB BS DHMSA Dip Phil is Honorary Senior Registrar in Psychiatry at the Bethlem Royal and Maudsley Hospitals, London and was previously Post-doctoral Research Fellow at the School of Medicine, Fohns Hopkins University, USA.

\section{References}

(1) The Ministry of Health. Working for patients. CM555: HMSO, 1989.

(2) Siu A L, Sonnenberg F A, Manning W G, et al. Inappropriate use of hospitals in a randomised trial of health insurance plans. New England journal of medicine 1986; 315:1259-1266.

(3) Rice T H, Labelle R J. Do physicians induce demand for medical services? Fournal of health politics, policy and law $1989 ; 14: 587-600$.

(4) Colloton J W. Academic medicine's changing covenant with society. Academic medicine 1989; 64:55-60.

(5) Povar G, Moreno J. Hippocrates and the health maintenance organisation - a discussion of ethical issues. Annals of internal medicine 1988; 109:419-424.

(6) Ginzberg E. A hard look at cost containment. New England journal of medicine 1987; 316:1151-1154.

(7) Relman A S. The allocation of medical resources by physicians. Fournal of medical education 1980; 55:99104.

(8) Yuan R T W. Confessions from the bottom. Plastic and reconstructive surgery 1988; 81:303-304.

(9) Novack D H, Detering B J, Arnold R, Forrow L, Ladinsky M, Pezzullo J C. Physicians' attitudes toward using deception to resolve difficult ethical problems. Fournal of the American Medical Association 1989;
261:2980-2985.

(10) Forrest J V, Lasser E C. Beer company more ethical than medical community? Radiology 1988; 166:901.

(11) Relman A S. Dealing with conflicts of interest. New England journal of medicine 1985; 313:749-751.

(12) Hyman D A, Williamson J V. Fraud and abuse - setting the limits on physicians' entrepreneurship. New England journal of medicine 1989; 320:1275-1278.

(13) Stark F H. Ethics in patient referrals. Academic medicine 1989; 64:146-147.

(14) Ross C E, Lauritsen J. Public opinion about doctors' pay. American journal of public health 1985; 75:668-670.

(15) Physician incomes. The psychiatric times 1990 Mar: 7: 71 (col 3).

(16) Wortis J. Conflicts of interest. Biological psychiatry 1988; 23:215-216.

(17) Dougherty C J. Ethical perspectives on prospective payment. Hastings Center report 1989 Jan/Feb: 5-11.

(18) Ginzberg E. The monetarization of health care. New England journal of medicine 1984; 310:1162-1165.

(19) Etheredge L. Ethics and the new insurance market. Inquiry 1986; 23:308-315.

(20) Habbersett C. Many in US denied health care due to lack of insurance. The fohns Hopkins university gazette 1990; 19: 7: (col 3).

(21) Cohodes D R. America: the home of the free, the land of the uninsured. Inquiry 1986; 23:227-235.

(22) Blendon R J. The public's view of the future of health care. Fournal of the American Medical Association 1988; 259:3587-3593.

(23) Freund D A, Allen K S. Factors affecting physicians' choice to practise in a fee-for-service setting versus an individual practice association. Medical care 1985; 23:799-808.

(24) Henry M C, Margulies J L, Olson C M. Economic triage: Emergency physicians should say 'no'. Annals of emergency medicine 1986; 15:983-984.

(25) Hamblin T J. A shocking American report with lessons for all. British medical journal 1987; 295:73.

(26) Rodning C B, Dacso C C. A physician/advertiser ethos. American journal of medicine 1987; 82:1209-1212.

(27) McKinlay J B, Arches J. Historical changes in doctoring: a reply to Milton Roemer. International journal of health services 1986; 16:473-477.

(28) Berrien R. What future for primary care private practice? New England journal of medicine 1987; 316:334-337.

(29) Geelhoed G W. In the healing business to look good. Southern medical journal 1988; 81:650.

(30) Thompson I E. Fundamental ethical principles in health care. British medical journal 1987; 295:1461-1465.

(31) Sigerst H L. On Hippocrates. Bulletin of the history of medicine 1934; 11:190-214.

(32) Spooner C E. On the importance of ethics. Fournal of medical education 1988; 63:339-340.

(33) Hippocrates: vol 1: 299-332 (translated by W H S Jones). The Loeb Classical Library. Cambridge: Harvard University Press, 1962.

(34) Sohl P, Bassford H A. Codes of medical ethics: traditional foundations and contemporary practice. Social science and medicine 1986; 22: 1175-1179.

(35) Gilder S S B. Ethics for doctors of the world. World medical journal 1982; 29: 95.

(36) Plotnikoff G A, Reynolds P P. The deprofessionalization of medicine. Fournal of the American Medical Association 1988; 259: 2238.

(37) Brandt-Rauf $\mathbf{P}$ W. Ethical conflict in the practice of 
occupational medicine. British journal of industrial medicine 1989; 46: 63-66.

(38) Howe K R. Medical students' evaluations of different levels of medical ethics teaching: implications for curricula. Fournal of medical education 1987; 21: 340349.

(39) Miller G D, Frank D, Franks R D, Getto C J. Noncognitive criteria for assessing students in North American medical schools. Academic medicine 1989; 64: 42-45.

(40) Royce P C. Medical ethics. Fournal of medical education 1987; 62: 619.

(41) Jonsen A R. Leadership in meeting ethical challenges.
Fournal of medical education 1987; 62: 95-99.

(42) Perkins H S, Bunnie S S. Impact of medical ethics consultations on physicians: an exploratory study. The American journal of medicine $1988 ; 85$ : 761-765.

(43) Alexander E, jr. Can medical ethics be taught? Surgical neurology 1988; 29: 416-423.

(44) Pellegrino E, Hart R, Henderson S, Loeb S, Edwards G. Relevance and utility of courses in medical ethics. Fournal of the American Medical Association 1985; 253: 49-51.

(45) Halper T. Life and death in a welfare state: end-stage $\vec{\circ}$ renal disease in the United Kingdom. Milbank Memorial Fund quarterly 1985; 63: 52-94.

\section{Dr John Dawson}

Dr John Dawson, head of the professional division of the British Medical Association and a member of the editorial board of the fournal of Medical Ethics, died in London on December 20, 1990, of cancer. He was 44. 